\title{
Pensar em Português
}

Ricardo Vélez Rodríguez ${ }^{1}$

A aventura do pensamento filosófico percorreu, na modernidade, o caminho das Filosofias Nacionais. Antes do advento dos tempos modernos, pensava-se em Grego ou em Latim. Com o surgimento dos Estados Nacionais e a substituição do Latim pelas línguas vernáculas, a Filosofia Ocidental passou a ser pensada nestas novas variantes da comunicação humana. Os pensadores deram renda solta às vivências locais, regionais e nacionais que se consolidaram na língua respectiva. O Pensamento Ocidental tingiu-se, definitivamente, com as cores da problemática humana vivenciada pelas Nações modernas. É meu propósito, neste artigo, discorrer sobre o tema, chamando a atenção, na parte final, para algumas características inéditas da aventura do pensar em Português, mais concretamente do Português falado no Brasil.

Dividirei a minha exposição em três partes: I - As Filosofias Nacionais e o estudo da Filosofia. II -Filosofias Nacionais e pensamento moderno. III - Características da aventura do Pensar em Português no Brasil.

\section{I - As Filosofias Nacionais e o estudo da Filosofia.}

O problema das Filosofias Nacionais é tema importante na evolução do pensamento contemporâneo. Não foi fácil chegar ao estágio atual de análise desapaixonada dessa questão. No contexto latino-americano, duas posições conflitantes poderíamos encontrar: a dos que simplesmente negaram a possibilidade da existência das Filosofias Nacionais, a partir do pressuposto de que o pensar filosófico ocidental teria já sido

${ }^{1}$ Professor Associado e Coordenador do Núcleo de Estudos Ibéricos e Ibero-americanos da Universidade Federal de Juiz de Fora. Membro-fundador da Academia Brasileira de Filosofia.

Brasiliana - Journal for Brazilian Studies. Vol. 2, n.1 (March. 2013). ISSN 2245-4373. 
formulado pelos pensadores europeus, cabendo-nos simplesmente a missão de reproduzir os seus ensinamentos. Tal é, por exemplo, a forma em que era entendido o estudo da Filosofia nas Universidades Católicas no mundo hispano-americano, até meados do século passado. A Ratio Studiorum jesuítica, vigente até então, praticamente excluía a possibilidade de uma abordagem direta da Filosofia em termos de problemas culturais nacionais.

De outro lado, encontramos a posição dos que valorizam excessivamente as possibilidades da meditação nacional, chegando ao extremo de colocá-la como algo totalmente original, desligado, portanto, da tradição filosófica ocidental. Pretender-se-ia, nas versões mais radicais, identificar, nas culturas pré-colombianas, longínquos vestígios para uma meditação autóctone; ou, também, assinalar o elo entre as condições peculiaríssimas do nosso subdesenvolvimento e um discurso filosófico que emergisse como original resposta dialética a essas circunstâncias, apregoando um tipo prático e revolucionário de libertação. Tal parece ser, por exemplo, a proposta de Enrique Dussel, ao formular a sua "filosofia da libertação" ou "ana-léctica da liberdade".(Cf. Vélez Rodrígues, 1987)

Entre esses dois extremos, situa-se o esforço desenvolvido pacientemente, ao longo dos últimos decênios, por crescente número de pensadores, no sentido de estudar a forma em que a tradição filosófica ocidental é retomada e recriada no contexto das diferentes culturas da América Latina. Seria difícil fazer, neste momento, uma enumeração completa dos autores mais representativos. Remeterei simplesmente a estudos que têm sido feitos a respeito, como a publicação, patrocinada pela Organização de Estados Americanos, em 1972, da obra intitulada: Los fundadores de la filosofia en la América Latina (Pacheco [org.]), ou a coletânea de ensaios publicada pela Sociedad Venezolana de Filosofia, em 1980, sob o título de: La filosofia en América (Mayz [org.]). 
Restringindo a análise ao campo brasileiro, poderia salientar as três contribuições que acho mais importantes, a fim de esclarecer o objetivo e os métodos para a elaboração de uma história nacional das idéias. O lugar de destaque cabe, sem dúvida, a Miguel Reale (1910-2006), cujo trabalho à frente do Instituto Brasileiro de Filosofia desde 1949, ensejou o cultivo do pensamento nacional, livre de uma atitude polêmica e aberto às mais diversas tendências. Antônio Paim (1927-) sintetizou assim a contribuição de Reale:

Ao antigo espírito polêmico, que alimenta como valor primordial a conquista da vitória no combate, sobrepôs-se o empenho de aprofundamento dos temas e problemas suscitados. A par disto, o professor Miguel Reale, presidente do Instituto, elaborou um método para o exame do pensamento brasileiro de comprovada eficácia. Consiste: $1^{\mathrm{o}}$ em identificar o problema (ou os problemas) que tinha pela frente o pensador, prescindindo da busca de filiações a correntes; $2^{\circ}$ em abandonar o confronto de interpretações e, portanto, o cotejo das idéias do pensador estudado com outras possíveis, para eleger entre uma ou outra; e, 3o em ocupar-se preferentemente da identificação de elos e derivações que permitam apreender as linhas de continuidade real de nossa meditação. Com semelhante espírito, alguns estudiosos conseguiram preencher lacunas, promover a reedição de textos e estabelecer novas hipóteses de trabalho. (Paim, 1979b:11)

Em segundo lugar, merece destaque a contribuição ensejada pela obra de Antônio Paim. Alicerçado na metodologia traçada por Miguel Reale, Paim desenvolveu ampla pesquisa tentando identificar os mais importantes problemas com que se defrontou o pensamento 
brasileiro. Em relação à importância que, na época hodierna, no seio da cultura brasileira, ganhou o estudo das filosofias nacionais, Paim frisa:

Com o processo de consolidação das nações e o abandono do Latim como língua oficial no mundo do saber ocorre, simultaneamente, a emergência das filosofias nacionais; estruturadas em torno de determinada temática que as singulariza. A par do que tem lugar na Inglaterra, Alemanha, França ou Itália, formam-se igualmente as filosofias portuguesa e brasileira. Estas, em seus momentos mais destacados, acabam sempre privilegiando o tema da moral e deixando marcas profundas em outras esferas do pensamento como a meditação acerca da política, da pedagogia, do direito, etc. Deste modo, a discussão dos fundamentos da moralidade, na Filosofia Moderna e Contemporânea, e a formação das filosofias nacionais constituem núcleo não exclusivo, mas de importância capital em nossa cultura. (Paim, 1983a:1)

Na obra já citada, O estudo do pensamento filosófico brasileiro, Paim sintetiza os principais resultados alcançados no relativo ao estudo dos principais problemas sobre os que se debruçou a meditação filosófica no Brasil.

Em terceiro lugar, é importante lembrar a contribuição do pensador português Eduardo Abranches de Soveral (1927-2003) ao estudo do tema das filosofias nacionais e suas implicações metodológicas. Alicerçado em aprofundada análise fenomenológica, Soveral traçou as linhas mestras do que, no seu entendimento, seria fundamental na metodologia filosófica para o estudo das filosofias nacionais (Cf. Soveral, 1979; 63-73). Sete itens considera essenciais Soveral para tal estudo: 1 - a determinação dos 
filosofemas; 2 - o estudo das formações históricas desses problemas; 3 - a análise do desenvolvimento lógico historicamente dado à vigência dessas soluções nos vários contextos sociais; 4 - a consideração do desenvolvimento histórico dado à vigência dessas soluções nos vários contextos sociais; 5 - a apreensão das novidades implicadas na formulação de novos filosofemas e / ou a reformulação de filosofemas já existentes; 6 - a explicação das articulações lógicas que determinaram os novos filosofemas ou a sua reformulação; 7 - a determinação da vigência dos novos filosofemas e / ou as suas modificações.

Referindo-se ao primeiro item, assim o explica Soveral:

A determinação de filosofemas, ou seja, de problemas que, equacionados a partir das interrogações mais amplas e radicais que se abrem ao espírito do homem, exigem soluções inteligíveis e exaustivamente fundamentadas. (Soveral, 1979; 63)

O ponto de partida da metodologia apresentada pelo pensador português coincide, em essência, com a metodologia assinalada por Reale para o estudo do pensamento brasileiro. Trata-se de não prejulgar acerca da filosofia de determinado autor, mas de ouvi-lo, tratando de entender a problemática a que pretende responder.

\section{II - Filosofias Nacionais e pensamento moderno.}

Existe uma Filosofia Brasileira? A esta pergunta pode-se dar dois tipos de respostas positivas: a primeira, arrolando os autores que, desde o período colonial, se têm ocupado em discutir a problemática do existir do homem e do mundo, numa perspectiva filosófica. A segunda, inquirindo acerca da forma assumida pela meditação 
filosófica no início da Idade Moderna, após a dissolução da unidade lingüística, religiosa e filosófica, que campeou na Europa ao longo da Idade Média. Esta resposta mostraria que o pensamento moderno emergiu tingido de Filosofias Nacionais. Aplicando o princípio escolástico de que "ab esse ad posse valet illatio" teríamos que, se as Filosofias Nacionais são um fato, a questão da Filosofia Brasileira se insere nesse contexto.

A questão da possibilidade da Filosofia Brasileira tem sido debatida de forma sistemática pela Corrente Culturalista, notadamente, como foi frisado no item anterior, por Miguel Reale ${ }^{2}$ e Antônio Paim ${ }^{3}$. Ilustrarei, a seguir, dois aspectos que acompanham o surgimento das filosofias nacionais: 1 - A crise da unidade cultural, decorrente da paulatina substituição do Latim pelas línguas vernáculas, e 2 - As novas questões emergentes no pensamento moderno.

1 - A crise da unidade cultural decorrente da paulatina substituição do Latim pelas línguas vernáculas. É sabido que, ao logo da Idade Média, o Latim que se falava nas Universidades não correspondia à versão clássica de Horácio, Tito Lívio, Virgílio e Cícero. Assim como a Língua Grega conheceu duas versões, o elegante Dialeto Ático em que escreveram os grandes poetas e a versão tardia conhecida como Koiné ou Língua

\footnotetext{
${ }^{2}$ Coube a Reale a iniciativa pioneira de indicar a forma em que se processou a inspiração brasileira na filosofia européia, sem que isso significasse cópia literal dela. Cf., a respeito, o seu ensaio intitulado: $A$ doutrina de Kant no Brasil - Notas à margem de um estudo de Clóvis Bevilácqua, São Paulo: Revista dos Tribunais, 1951.

${ }^{3}$ Cf. PAIM, Antônio. O estudo do pensamento filosófico brasileiro, ob. cit. Paim desenvolveu amplo trabalho bibliográfico em relação ao Pensamento Filosófico Brasileiro, segundo se pode concluir da leitura das seguintes obras de sua lavra: Bibliografia filosófica brasileira - 1808-1930, Salvador-Bahia: Centro de Documentação do Pensamento Brasileiro, 1983; Bibliografia filosófica brasileira - Período contemporâneo 1931-1977, São Paulo: Editora GRD; Brasília: Instituto Nacional do Livro, 1979. No terreno da organização documental, o maior esforço corresponde ao Centro de Documentação do Pensamento Brasileiro, sediado em Salvador-Bahia, organizado por Antônio Paim, em 1982, a partir da doação da biblioteca pessoal do pensador, efetivada em 1982. Cf., a respeito, Antônio PAIM, (organizador), Catálogo do acervo, Salvador-Bahia: Centro de Documentação do Pensamento Brasileiro, 1985.
}

Brasiliana - Journal for Brazilian Studies. Vol. 2, n.1 (March. 2013). ISSN 2245-4373. 
Comum (em que foi vertido o Novo Testamento e em que foi escrita a obra de Aristóteles), o Latim conheceu duas variantes: a Clássica e a denominada de Latim Vulgar. Este ultimo constituiu o veículo de comunicação nas Universidades Medievais, e nele foram escritas as principais obras da Filosofia Escolástica. Assim, Pedro Abelardo, Alberto Magno, Tomás de Aquino, Boaventura, Duns Scot, Guilherme de Ockham, etc. utilizaram essa forma da Língua Latina.

O Latim Vulgar (Cf. Erradonea, 1954:956 v.II) é uma variante da clássica Língua Latina, inspirada no seu sistema vocálico, mas diferente desta, porque a expressão cuidadosamente polida dos grandes poetas e prosistas não era entendida pela massa, que falava uma língua menos cuidada. Não devemos, no entanto, buscar a origem do Latim Vulgar no chamado "Baixo Latim” dos notários merovíngios. Assinalar uma data para fixar a Antigüidade do Latim Vulgar é empresa muito difícil. De uma maneira geral, pode-se assinalar como período em que aconteceu a sua difusão, o século II do Império. Contribuíram para isso a criação de colônias com veteranos das legiões, naquelas regiões dominadas por Roma e, de outro lado, a pregação do Cristianismo. Esta nova religião, tendo buscado os seus prosélitos entre pessoas de humilde condição principalmente, obrigou os primeiros escritores cristãos a se comunicarem no dialeto popular e a introduzirem, assim, uma fala cheia de vulgarismos, ao lado do Latim literário da decadência do Império.

A relação das duas línguas, a clássica e a vulgar, se revela no sistema vocálico, que conservou a acentuação na penúltima ou antepenúltima vocal, mesmo depois de perdida a quantidade, na mesma vocal. Na morfologia, foi simplificada a declinação dos substantivos e adjetivos, da mesma forma que a conjugação dos verbos. Na sintaxe, a livre colocação dos termos da proposição cedeu lugar a um sistema construtivo, que não permitia a separação arbitrária dos vocábulos.(Cf. Erradonea, 1954: 956-8. Vol II) Ao 
elegante período ciceroniano: "Quousque tandem abutere, Catilina, patientia nostra?" sucede o cotidiano: "Respondeo dicendum quod" das Summas medievais.

O Latim Vulgar permaneceria, ao longo da Idade Média, vinculado às necessidades pedagógicas da Igreja. A estabilidade do saber estava garantida pela prelação que tinha a Teologia sobre outras formas de conhecimento. O papel do Latim Vulgar como veículo para o acesso ao conhecimento da tradição eclesial e da liturgia, vinculava-se a essa alta finalidade teológica e religiosa. O trivium e o quadrivium medievais, longe de serem um tirocínio na cultura clássica em si, estavam destinados, basicamente, a manter viva a tradição da Igreja.(Cf: Bréhier, 1978:38)

O caráter instrumental que desempenharam o Latim e, em geral, a cultura clássica, ao longo da Idade Média, abriu as portas para a paulatina substituição da Língua do Lácio pelas vernáculas, quando entrou em crise a síntese da escolástica medieval. Elemento fundamental dessa crise foi, sem dúvida, o espírito do Nominalismo que, de forma análoga aos antigos céticos, se insurgiu contra a hegemonia dos grandes sistemas metafísicos e aderiu à dúvida perante essa realidade. Assim caracterizou Bréhier essa reação:

Temos pela frente, nos séculos XIV e XV, ao lado de espirituais e místicos, homens práticos e lógicos, de espírito frio e sóbrio, que perderam o entusiasmo religioso animador das gerações das grandes cruzadas e adquiriram, na complicada diplomacia que exige nessa época o menor assunto, esse espírito claro e positivo que caracteriza sua doutrina. $\mathrm{O}$ nominalismo dessa época é algo muito diferente de uma solução particular do problema dos universais: é um espírito novo que desconfia das realidades metafísicas que os peripatéticos e os platônicos acreditavam haver descoberto, que se atém, tanto quanto possível, à 
experiência e, sem rejeitar as verdades da fé, consideram-nas, em geral, heterogêneas e inacessíveis à razão. (Bréhier, 1978:183-4)

A crítica ensejada pelos Nominalistas, notadamente por Guilherme de Ockham (12801349) ao peripatetismo, especialmente à doutrina dos universais, marca o início da crise da escolástica. Alguns Nominalistas como Nicolau Oresme (que estudava Teologia em Paris em 1348 e faleceu em 1382 como bispo de Lisieux) começaram a escrever os seus tratados em língua vulgar. Oresme escreveu o Comentário aos livros do céu e do mundo em que, além de criticar a física que se ensinava na Idade Média, formulava conceitos como o de coordenadas (que posteriormente foi desenvolvido por Descartes) e descobriu a fórmula exata do espaço percorrido por um corpo que cai em movimento uniformemente acelerado. Galileu posteriormente trabalhou sobre esta fórmula. (Cf: Koiré, 1966:60-94) Vê-se, neste caso, de que forma, ao passo que a problemática filosófica muda (conferindo autonomia à observação científica), evolui também a forma de se comunicar essa problemática: passa-se do Latim à língua vernácula.

Esfacela-se a unidade cultural da Europa medieval, representada na unidade de temática e de perspectiva das grandes sínteses da Escolástica. Ao lado do surgimento das línguas nacionais como formas de comunicação no mundo da cultura, aparecem problemáticas bem típicas das diferentes nacionalidades. Poderíamos mencionar alguns aspectos desse novo perfil cultural: o primado da experiência no mundo anglo-saxão; a questão religiosa da interpretação das Escrituras na Alemanha de Lutero; a virtù, entendida como dimensão puramente humana e a visão do Estado como obra de arte, na Itália de Maquiavel; o agravamento da polêmica acerca das relações entre fé e razão (em decorrência do legado dos averroistas latinos e dos questionamentos dos Nominalistas), na Universidade de Paris; o sentido de missão que empolga aos 
nascentes impérios espanhol e português, consolidados numa luta secular contra o invasor muçulmano, etc.

Um fenômeno que mostra a perda da unidade cultural da Europa é a progressiva preferência dos pensadores pela língua nacional. Ao passo que um filósofo da projeção de Leibniz (1646-1716) escreve as suas primeiras dissertações em Latim (De principio individui, 1663; Dissertatio de arte combinatoria, 1666; Hypothesis de physica nova, 1671; Theoria motus abstracti, 1671), reserva para a língua vulgar os seus mais importantes tratados (Discours de Métaphysique, 1686; Système nouveau de la nature, 1695; Considérations sur la nature d' un esprit universel, 1697; Nouveaux essais sur l'entendement humain, 17011704; Essais de Théodicée sur la bonté de Dieu, la liberté de l'homme et l'origine du mal, 1710, Monadologie, 1714, Principes de la nature et de la grâce fondés en raison, 1719).

Fenômeno semelhante encontramos num contemporâneo de Leibniz, sir Isaac Newton (1642-1727). Sabe-se da importância que o grande físico dava às questões teológicas. Este autor escreveu em Inglês justamente a parte da sua obra relativa a esse item, sobressaindo o livro Observations on the prophecies of Daniel and the Apocalypse of St. John (publicado em 1733). A parte científica da sua obra foi escrita em Inglês (Optick, 1704) e em Latim (Philosophiae naturalis principia mathematica, 1687).

2 - As novas questões emergentes no pensamento moderno. À perda da unidade cultural da Europa, ensejada pela ascensão das línguas vernáculas e o recuo do Latim correspondeu, também, outro fenômeno: os pensadores passaram a se questionar, nos diversos países, acerca de problemáticas até então desconhecidas, desvinculadas da questão teológica que encampou o discurso ao longo da Idade Média. O novo espírito do tempo pode muito bem ser exemplificado na descrição que Leonardo da Vinci (nascido em 1452) faz da sabedoria: ela não se encontra no antigo saber escolástico, mas 
nos conhecimentos obtidos da experiência. A respeito, frisa o artista e pensador renascentista:

Mesmo que eu não soubesse (...) invocar o testemunho dos autores, citarei algo muito maior e mais digno, invocando o testemunho da experiência, mestra dos mestres mesmos. Estes andam envaidecidos e pomposos, vestidos e enfeitados, não com as suas próprias fadigas, mas com as alheias, e não querem conceder as mesmas a mim mesmo. E se menosprezam a mim, inventor, quanto mais não poderiam ser censurados eles, que não são inventores, mas pregoeiros e recitadores das obras alheias? (Apud: Mondolfo, 1967: 21-22)

Sem dúvida alguma que a Reforma Protestante significou um passo de importância capital no surgimento das novas questões que empolgariam, doravante, a meditação filosófica. O movimento empreendido por Martinho Lutero (1483-1546) na Alemanha, além de ter representado a primeira grande tentativa de valorização da língua alemã, ensejou, com a tradução do texto sagrado para a língua vernácula e a instituição do livre exame, o primeiro passo de independência do indivíduo em relação à tradição controlada pela Igreja. O primeiro direito individual a ser conquistado no mundo moderno foi este: o de se relacionar pessoalmente com Deus e o de interpretar, no silêncio da própria consciência, as Sagradas Escrituras. É a primeira grande conquista do individualismo, que será continuada, nos séculos vindouros, por outras conquistas, até se chegar à formulação dos direitos inalienáveis dos indivíduos à vida, à liberdade e às posses, de que se desincumbiria a filosofia inglesa dos séculos XVII e XVIII com Locke, Shaftesbury, Hume, etc. 
Outra questão emergente é a dicotomia moral-religião e a formulação da moral social de cunho consensual na Inglaterra. Quanto ao primeiro aspecto da questão, a dicotomia entre moral e religião, um passo fundamental é dado na Itália, ao longo dos séculos XV e XVI. Maquiavel (1467-1517) será o grande formulador dessa mudança. Contrapondo-se à tentativa ensejada por Savonarola (1452-1498), no sentido de organizar a República de Florença em bases teocráticas, Maquiavel considerava que uma nova ordem de valores devia presidir a construção do Estado. Este possui, entre as suas características fundamentais, o uso da violência. Maquiavel formulou uma nova moral de cunho político, que olhava para o resultado da ação e não tanto para as intenções do agente. É o que Max Weber (1864-1920) denominou posteriormente de "ética de responsabilidade", que se diferencia da "ética de convicção".(Cf. Weber, 1986) Para o homem da Renascença Italiana, como frisou Jacob Burckhardt (Cf: Burckhardt, 1877: 7-17), o Estado é uma obra de arte que responde a um projeto individual do príncipe. Este deve, antes de tudo, ser virtuoso, no sentido greco-romano do termo, ou seja, capaz de governar e de garantir segurança e tranqüilidade para a Polis.

Essa mudança fundamental realizada na Itália renascentista, ao desvincular a moral política da religião, foi continuada posteriormente na Inglaterra. A partir do século XVI vamos encontrar, nas Ilhas Britânicas, a preocupação com a fundamentação de uma moral independentemente da religião e que fosse formulada pela sociedade, através de um consenso. As figuras mais importantes desse empenho foram Anthony Ashley Cooper, conde de Shaftesbury (1671-1713), John Locke (1632-1704), David Hume (1711-1776) e Adam Smith (1723-1790). Outros representantes dessa tendência foram Francis Hutcheson (1664-1746), Joseph Butler (1692-1752) e Bernard de Mandeville (1670-1733). A discussão da moral social acompanhou, na Inglaterra do século XVII, as questões da representação e da tolerância, amplamente formuladas por Locke nas suas 
Cartas sobre a tolerância (Cf.: Locke, 1996) e o Segundo tratado sobre o governo civil (1690). (Cf.: Locke, 1998)

Uma outra questão emergente foi colocada pelo projeto ibérico de alargar as fronteiras culturais sobre os outros Continentes, no contexto do magno esforço colonizador ensejado pela Espanha e Portugal ao longo dos séculos XVI e XVII. Consoante Richard Morse,

(...) A guinada espanhola em direção ao tomismo no século XVI - ou seja, em direção a uma visão do mundo do século XIII, que unicamente tinha conquistado adesões esparsas nos três séculos intermediários -, explica-se precisamente pela modernidade da situação histórica da Espanha, ou seja, pela exigência com que se defrontava de conciliar uma racionalidade para um Estado moderno com as afirmações de uma ordem mundial ecumênica, ou de adaptar os requerimentos da vida cristã à tarefa de incorporar povos não cristãos à civilização européia. (Morse, 1982:47)

O caso de Portugal era, no sentir do citado autor, semelhante ao da Espanha, embora o papel cartorial do Estado fosse mais marcante. A respeito, frisa Morse: “(...) A maior homogeneidade do país, a sua consolidação mais antiga, a monarquia mais centralizada, as aventuras civilizadoras menos ambiciosas do país em ultramar, tudo se combinava para limitar os horizontes efetivos da atividade intelectual". (Morse, 1982:47)

Os dois aspectos analisados revelam que, no início da Idade Moderna, ficou aberta a porta para uma forma diferente de fazer filosofia, a partir das peculiaridades

\footnotetext{
${ }^{4}$ Foram, ao todo, três cartas, publicadas a primeira em 1660, a segunda em 1670 e a terceira em 1679.
} 
assumidas pela meditação dos autores sobre novas questões emergentes, no seio das várias nações. A quebra da unidade lingüística e a adoção das línguas vernáculas favoreceram o processo diferenciador, na discussão dos problemas. A pesquisa iniciada pelos culturalistas, no Brasil, em relação ao pensamento nacional alargou-se ao pensamento português, tarefa de que se desincumbiu, ao longo dos últimos trinta anos, a geração de pesquisadores formados na Universidade Gama Filho, no início da década de 80 do século passado, por Antônio Paim e Eduardo Abranches de Soveral, ao ensejo do Programa de Pós-graduação em Pensamento Luso-brasileiro. Leonardo Prota, na Universidade Estadual de Londrina e nos Encontros Nacionais de Professores e Pesquisadores da Filosofia Brasileira (por ele organizados no período compreendido entre 1989 e 2001), fez amplo balanço do caminho tomado pelas principais filosofias nacionais, destacando as semelhanças e as diferenças em face da meditação brasileira. (Cf.: Prota, 1989-2003. 7 vols.)

\section{III - Características da aventura do Pensar em Português no Brasil.}

Quando falamos à luz do Lógos, damos vazão às nossas crenças fundamentais. Ora, quais seriam, no caso da meditação filosófica brasileira, essas crenças que deram ensejo às nossas idéias mestras? Considero que, no caso, entraram na torrente da nossa reflexão duas séries de convicções alicerçadas sobre crenças profundas: primeiro, retomando a herança portuguesa da "filosofia da saudade", uma linha de pensamento com raízes neoplatônicas e barrocas, que terminou desaguando na denominada "Escola de São Paulo". Constitui o núcleo doutrinário dessa tendência, a crença radical de que há um arquétipo preexistente ao qual tudo deve ser referido para ter validade e, paralelamente, de que houve uma "queda" da atual feição da realidade, que constituiria, assim, cópia imperfeita da plenitude ôntica de um passado primordial que cumpre reviver, mediante 
um processo catártico de índole pitagórico-platônica. Constitui esta variante uma retomada do neoplatonismo. Essa linha de pensamento se formou hodiernamente, no caso brasileiro, ao redor do pensamento de Vicente Ferreira da Silva (1916-1963) (Cf.: Silva, 1964), que elaborou uma filosofia com tintes órficos e numinosos de intuição do mistério do Ser, dando continuidade, na nossa meditação, à rica tradição ensejada pela "metafísica da saudade", tão densa na meditação portuguesa moderna e contemporânea, que aflora hoje na tendência denominada da "filosofia portuguesa", fartamente estudada por Antônio Braz Teixeira e, mais recentemente, por uma geração de jovens pensadores aglutinados ao redor da revista Nova Águia, editada no Porto sob os cuidados da jovem pensadora Celeste Natário.

A segunda linha de pensamento passou a girar ao redor de outra herança portuguesa: a do Iluminismo consolidado na obra pombalina e na sua reforma educacional, que afetou profundamente as nossas instituições de ensino e a meditação filosófica, tendo-as condicionado ao que se denominou de paradigma do "empirismo mitigado" e da postura "cientificista". Consolidou-se tal tendência à luz da crença de que haveria uma ciência primordial de índole prática, à qual deveria ser referido todo o arcabouço do saber, a ser administrado por um líder, no contexto da concepção do despotismo ilustrado. Velha reencarnação do iluminismo absolutista ensejado na França por Luís XIV que, em Portugal, encontrou o seu ponto alto no reinado de Dom José I e do seu primeiro-ministro o marquês de Pombal, Sebastião José de Carvalho e Mello, na segunda metade do século XVIII. A manifestação contemporânea de tal tendência na meditação brasileira se dá na corrente do cientificismo marxista que, misturada a formas agressivas de leninismo, como o pensamento gramsciano, encontrou canais de realização política na era lulopetista (Cf.: Paim, 2002), que se assenhoreou do poder a partir de 2002. Na seara doutrinária, tal corrente encontrou adequado canal de manifestação na “teologia da libertação" (Cf.: Vélez Rodríguez, 1987), um de cujos 
arautos, no terreno filosófico, foi o padre Henrique Cláudio de Lima Vaz (Cf.: Paim, 1979a). A manifestação mais abrangente dessa tendência do cientificismo no século XX foi, na realidade brasileira, a vertente conhecida como "segunda geração castilhista" (Cf.: Vélez Rodríguez, 2010), que encontrou em Getúlio Vargas (1883-1954) o seu mais importante demiurgo, que se alicerçou no positivismo gaúcho e no saint-simonismo, bem como na doutrina do "autoritarismo instrumental" formulada por Oliveira Vianna (1883-1951), da qual se louvou, outrossim, o regime militar (1964-1985) para a sua ação reformista (Cf.: Vélez Rodrígues, 1997).

Uma terceira linha de pensamento consolidou-se a partir da nossa experiência como Nação, que tentava construir o Estado como instrumento de integração dos clãs esparsos na vastidão continental das fronteiras, que foram estrategicamente alargadas sobre o Império espanhol, à luz do Tratado de Tordesilhas, mantendo a unidade nacional e a identidade lingüística. Essa experiência foi forjada pelos estadistas do Império e pela elite denominada por Oliveira Vianna de "Homens de Mil". A partir de tal instância cultural foi formulado o ecletismo espiritualista do século XIX por Domingos Gonçalves de Magalhães, visconde de Araguaia, que deitou os alicerces doutrinários para a obra civilizacional e a construção das Instituições do governo representativo, consolidadas no Segundo Reinado ${ }^{5}$. A crença fundamental que alimenta o arcabouço doutrinário desta tendência foi a de que somente na defesa intransigente da liberdade e da consciência individual seria possível construir, de forma duradoura, as instituições que garantissem a dignidade humana. Afinou-se assim, esta tendência com as modernas versões do liberalismo clássico de Locke, Kant, Jefferson, Tocqueville, etc., constituindo versão política alternativa ao democratismo rousseauniano.

\footnotetext{
${ }^{5}$ Síntese doutrinária de todo esse processo pode ser encontrada na clássica obra de Antônio Paim: História das idéias filosóficas no Brasil, 4ạ edição, São Paulo: Convívio; Brasília: Fundação Nacional Pro-Memória, 1984.
} 
A partir da crítica de Tobias Barreto e Sílvio Romero (os mais destacados representantes da denominada Escola do Recife) ao cientificismo de inspiração pombalina e positivista, estruturou-se a Corrente Culturalista que enriqueceu a convicção do ecletismo espiritualista em prol da liberdade e da consciência individual com o desenvolvimento doutrinário de Kant (1723-1804) e do neokantismo. Esta escola de idéias, ${ }^{6}$ cujos máximos representantes na atualidade são Miguel Reale e Antônio Paim é, sem dúvida, a que maior envergadura tem mostrado no que tange à sua vitalidade e à função crítica, tanto dos dogmatismos quanto do autoritarismo que, no ciclo republicano, forjou-se nos vários momentos em que se tentou reeditar a "ditadura científica" (cf: Paim, 2006).

\section{Bibliografia}

Bréhier, Émile. História da filosofia. (Trad. de E. Sucupira Filho). São Paulo: Mestre Jou, 1978.

Burckhardt, Jacob. La civilisation en Italie au temps de la Renaissance. (Versão francesa de M. Schimitt). Paris: Plon, 1877.

Errandonea, Ignacio. Diccionario del Mundo Clásico. Barcelona: Labor, 1954, vol. II, p. 956.

Koiré, Alexandre. Études galiléennes. Paris: Herman, 1966.

Locke, John. Carta sobre a tolerância, (Prefácio, introdução e notas do Institut International de Philosophie e Presses Universitaires de France; tradução de João da Silva Gama). Lisboa: Edições 70, 1996.

. Dois tratados sobre o governo. (Tradução de Julio Fischer; introdução e notas de Peter Laslett). São Paulo: Martins Fontes, 1998.

\footnotetext{
${ }^{6}$ Síntese das idéias desta corrente encontra-se na obra de Antônio PAIM: A corrente culturalista, 2ạ edição, São Paulo Convívio, 1984.
}

Brasiliana - Journal for Brazilian Studies. Vol. 2, n.1 (March. 2013). ISSN 2245-4373. 
Mayz Vallenilla, Ernesto (organizador). La filosofia en América. Caracas: Sociedad Venezolana de Filosofia, 1980, 2 vol.

Mondolfo, Rodolfo. Figuras e idéias da filosofia da Renascença. (Tradução de Gomes da Mota). São Paulo: Mestre Jou, 1967.

Morse, Richard. El espejo de Próspero: un estudio de la dialéctica del Nuevo Mundo. (Trad. De Stella Mastrangelo). México: Siglo XXI, 1982.

Pacheco, Armando Correia (organizador). Los fundadores de la filosofia en la América Latina. Washington: Organization of American States, 1972.

Paim, Antônio (organizador). Liberdade acadêmica e opção totalitária: um debate memorável. Rio de Janeiro: Artenova, 1979a.

. O estudo do pensamento filosófico brasileiro. $1^{\text {a }}$ edição. Rio de Janeiro: Tempo Brasileiro, 1979b, p. 11.

. Bibliografia filosófica brasileira - Período contemporâneo 1931-1977, São Paulo:

Editora GRD; Brasília: Instituto Nacional do Livro, 1979c.

- A pós-graduação em filosofia na Universidade Gama Filho. Rio de Janeiro: Universidade Gama Filho - Departamento de Filosofia, 1983a, p. 1. Documento de trabalho.

- Bibliografia filosófica brasileira - 1808-1930, Salvador-Bahia: Centro de Documentação do Pensamento Brasileiro, 1983b. . A corrente culturalista, 2a edição, São Paulo Convívio, 1984a.

. História das idéias filosóficas no Brasil, 4⿳亠丷a edição, São Paulo: Convívio; Brasília: Fundação Nacional Pro-Memória, 1984.

. (organizador). Catálogo do acervo. Salvador-Bahia: Centro de Documentação do Pensamento Brasileiro, 1985.

. Para entender o PT. Londrina: Edições Humanidades, 2002. . A corrente cientificista. Londrina: Edições Humanidades, 2006. 
Prota, Leonardo (organizador). Anais dos Encontros Nacionais de Professores e Pesquisadores da Filosofia Brasileira - 1989-2001. Londrina: Universidade Estadual de Londrina / Centro de Estudos Filosóficos de Londrina (CEFIL), 1989-2003, 7 volumes.

Reale, Miguel. A doutrina de Kant no Brasil - Notas à margem de um estudo de Clóvis Bevilácqua, São Paulo: Revista dos Tribunais, 1951.

Silva, Vicente Ferreira da. Obras completas. Apresentação de Miguel Reale. São Paulo: Instituto Brasileiro de Filosofia, 1964, 2 volumes.

Soveral, Eduardo Abranches de. "Epistemologia da história: o caso particular de uma História Nacional das Idéias". Presença filosófica, Rio de Janeiro: Sociedade Brasileira de Filósofos Católicos, vol. V, no 3 (Julho-Setembro 1979): p. 63-73.

Vélez Rodríguez, Ricardo. Pensamento político brasileiro - Período contemporâneo. (Apresentação do Cel. Aviador Araken Hipólito da Costa). Rio de Janeiro: Clube da Aeronáutica, 2012.

- Castilhismo, uma filosofia da República. 3a edição revista e ampliada. Brasília: Senado Federal, 2010.

. Oliveira Vianna e o papel modernizador do Estado brasileiro. Londrina: Editora da Universidade Estadual de Londrina, 1997.

. "Politischer Messianismus und Theologie der Befreiung", in: R. HOFFMAN (organizador). Gottesreich und Revolution, Münster: Bonifatius, 1987.Weber, Max. Ciência e política, duas vocações. (Tradução de Leônidas Hegenberg e Octany Silveira da Mota), 3ª edição, São Paulo: Cultrix, 1986. 